\title{
A PROTEÇÃO AMBIENTAL DOS ANIMAIS EM CONFLITO COM OUTROS DIREITOS FUNDAMENTAIS SOB A PERSPECTIVA DESENVOLVIMENTO SUSTENTÁ VEL COM BASE NA JURISPRUDÊNCIA DO SUPREMO TRIBUNAL FEDERAL
}

\author{
Alan Felipe Provin ${ }^{1}$ \\ Isadora Kauana Lazaretti**
}

\section{RESUMO}

O presente artigo tem como objetivo geral a tarefa de analisar a ponderação de conflitos entre a proteção animal com outros direitos fundamentais, como, por exemplo, manifestação cultural e liberdade religiosa, com base em precedentes do STF sob a perspectiva do desenvolvimento sustentável. Especificamente, busca-se compreender a existência de conflitos entre direitos fundamentais; e, ainda, analisar as decisões proferidas pelo STF no âmbito da proteção dos animais e a relativização de direitos fundamentais. A pesquisa tem caráter qualitativo, e adotou-se o método indutivo, utilizando-se a técnica de pesquisa bibliográfica.

Palavras-chave: desenvolvimento sustentável; proteção animal; direitos fundamentais; colisão de direitos; Supremo Tribunal Federal.

\section{THE ENVIRONMENTAL PROTECTION OF ANIMALS AGAINST OTHER FUNDAMENTAL RIGHTS UNDER THE PERSPECTIVE OF SUSTEINABLE DEVELOPMENT BASED ON THE JURISPRUDENCE OF THE SUPREME FEDERAL COURT}

\begin{abstract}
The objective of this article is to analyze the balance of conflicts between animal protection with other fundamental rights, such as cultural manifestation and religious freedom, based on precedents of the STF under the perspective of sustainable development. Specifically, it seeks to understand the existence of conflicts between fundamental rights; and to analyze the decisions of the STF in the field of animal protection and the relativization of fundamental rights. The research has a qualitative character, and the inductive method was adopted, using the technique of bibliographical research.
\end{abstract}

Keywords: sustainable development; animal protection; fundamental rights; collision of rights; Supreme Federal Court.

\section{INTRODUÇÃO}

\footnotetext{
1 Doutorando em Ciência Jurídica pela Universidade do Vale do Itajaí (UNIVALI). Endereço eletrônico: alanprovin@hotmail.com. Endereço Postal: Rua do Comércio, 1329, Sala 02, Centro, Modelo/SC.

** Mestre em Direito pela Universidade Comunitária da Região de Chapecó (UNOCHAPECÓ). Endereço eletrônico: isadoralazaretti@hotmail.com. Endereço postal: Rua Herculano H. Zanuzzo, n. 632, Sala 02, Bairro Industrial, Seara/SC.
} 
O presente artigo versa sobre o estudo do conflito entre a proteção animal e outros direitos fundamentais, a partir de uma análise realizada de entendimentos proferidos pelo Supremo Tribunal Federal envolvendo a colisão de direitos e princípios constitucionais fundamentais no âmbito da proteção à vida não humana.

O desenvolvimento sustentável tornou-se um tema que tem atraído interesses nos mais variados campos. Seu conceito vem sendo, inclusive, objeto de discussão nas decisões judiciais proferidas pelo Supremo Tribunal Federal em casos que envolvem a proteção do meio ambiente e o conflito desse direito fundamental com outros direitos que possuem o mesmo tratamento constitucional.

Este artigo levanta a problemática acerca de como seria ponderar o conflito entre a proteção animal com outros direitos fundamentais, a partir da análise do pronunciamento do STF em situações que envolvem a proteção animal e o direito ao meio ambiente ecologicamente equilibrado com outros direitos fundamentais, como, por exemplo, manifestação cultural e liberdade religiosa. Trata-se, especificamente, de casos concretos que se tornaram objeto de discussão judicial na Corte Suprema, que envolvem a proteção dos animais, como, por exemplo, a farra do boi, rinhas de galo e o sacrifício de animais em rituais religiosos.

A temática escolhida como objeto de estudo mostra-se importante por se tratar de um debate contemporâneo, na medida em que tais discussões ocorrem atualmente no âmbito do STF, e sua alta projeção na sociedade brasileira enfrenta uma realidade complexa e altamente dinâmica que está em constante transformação na sociedade atual. Dessa forma, o objetivo geral da presente pesquisa consiste em analisar o conflito da proteção animal com outros direitos fundamentais elencados na Constituição Federal sob a perspectiva do desenvolvimento sustentável a partir de precedentes do Supremo Tribunal Federal. Especificamente, tem-se como objetivos a tarefa de compreender os conflitos entre o direito ambiental e desenvolvimento sustentável com outros direitos fundamentais e, ainda, analisar as decisões do STF no âmbito da proteção aos animais e a relativização de direitos fundamentais.

Para alcançar os objetivos propostos, faz-se necessária a divisão da presente pesquisa em dois itens estruturados na sequência. No primeiro item, estuda-se o direito ao meio ambiente como um direito fundamental e o desenvolvimento sustentável enquanto seu desdobramento, sua categoria conceitual e os debates contemporâneos que envolvem o tema. 
Para tanto, também se aprofunda a discussão acerca da possibilidade da ocorrência de conflitos entre desenvolvimento sustentável e outros direitos fundamentais elencados na Constituição Federal. O segundo tópico pretende analisar as decisões do STF que envolvem a proteção dos animais e a relativização de direitos fundamentais, a partir da observação de precedentes da Suprema Corte envolvendo colisão de direitos entre proteção animal, manifestação cultural e liberdade religiosa. Nesse tópico, serão analisadas decisões proferidas pelo STF nos últimos anos e qual o posicionamento adotado pelos julgadores diante de aparente conflito de direitos fundamentais.

Para o desenvolvimento da presente pesquisa, foram observados procedimentos metodológicos consistentes na adoção do método dedutivo. A pesquisa, por sua vez, tem caráter qualitativo e a técnica de pesquisa utilizada foi a bibliográfica, com base na análise de livros, artigos científicos, documentos eletrônicos e decisões judiciais extraídas da base de dados da jurisprudência do Supremo Tribunal Federal.

\section{OS CONFLITOS ENTRE DIREITO AMBIENTAL E DESENVOLVIMENTO SUSTENTÁVEL COM OUTROS DIREITOS FUNDAMENTAIS}

A proteção do direito ao meio ambiente ecologicamente equilibrado existe como forma de favorecer o próprio homem e com a finalidade de proteger as demais espécies (FIORILLO, 2011).

Do ponto de vista da positivação desse direito na Constituição Federal de 1988, o constituinte, ao tratar de forma específica do direito ao meio ambiente, elencou como fundamental a premissa de que "todos tem direito ao meio ambiente ecologicamente equilibrado", considerando o meio ambiente como um "bem de uso comum do povo", e, ainda, visto como algo "essencial à sadia qualidade de vida". O constituinte impôs no mencionado texto constitucional a obrigação do Poder Público de defender e preservar o meio ambiente para as presentes e futuras gerações" (BRASIL, 1988).

Garantido como um direito fundamental, o direito ao meio ambiente ecologicamente equilibrado também se classifica como um direito humano de terceira geração, se analisado do ponto de vista da evolução dos direitos. Contudo, apesar de não estar inserido no capítulo dos Direitos Fundamentais, a breve análise global dos preceitos constitucionais que se relacionam com a proteção ambiental torna possível concluir que existe uma "verdadeira 
consagração de uma política ambiental, como também um dever jurídico constitucional atribuído ao Estado" (LEITE, 2002, p. 86-87).

Enquanto um direito difuso, na medida em que pertence a uma coletividade enquanto tal, isto é, não possuem titularidade singularizada, o meio ambiente é considerado um direito de solidariedade, na concepção de Ferreira Filho (2011). Mirra (2002) ainda considera que a qualidade de direito fundamental do meio ambiente é assim destacada pelo reforço dos regimes jurídicos que tratam o meio ambiente como um bem de uso comum do povo e dos bens ambientais e por todas as medidas existentes destinadas à proteção desse patrimônio coletivo.

Com o passar dos anos, problemas ambientas relacionados com o esgotamento dos recursos naturais, impactos negativos da degradação do meio ambiente, escassez da água, perda da biodiversidade, mudanças climáticas, aumento da temperatura global e o aumento do nível do mar tornaram o meio ambiente um assunto desafiador, uma vez que passou-se perceber que a sobrevivência humana e dos sistemas biológicos do planeta estão ameaçados.

A partir dessa preocupação, emerge o debate da sustentabilidade, que perpassa a ideia central de que as decisões e as ações atuais não devem prejudicar as futuras gerações quanto às suas perspectivas de qualidade de vida. A preocupação com as futuras gerações foi destacada por Hans Jonas, a partir da proposição da "ética da responsabilidade", baseada no fato de que os avanços tecnológicos e o vazio ético da sociedade contemporânea resultam no poder do homem para prejudicar as futuras gerações a partir da destruição ambiental (JONAS, 2003).

Pode-se afirmar que a sustentabilidade está relacionada com desenvolvimento econômico, qualidade ambiental e equidade social. Pode ser definida como "a característica de um processo ou sistema que permite que ele exista por certo tempo ou por tempo indeterminado". O termo "sustentabilidade" tornou-se um princípio do qual a utilização de recursos naturais, destinados à satisfação das necessidades do homem não podem comprometer a satisfação das necessidades das futuras gerações (BARBOSA, 2011, p. 66).

Campinho (2010) considera que a sustentabilidade abrange outros bens que devem servir de orientação, parâmetro e limite para o desenvolvimento econômico, humano e social. Não se pensa apenas na questão ambiental, porque o conceito de sustentabilidade abarca uma série de fatores que ultrapassam o meio ambiente, como o patrimônio comum da humanidade, a paz e a própria defesa da democracia e dos direitos humanos. 
Ao pensar em sustentabilidade, faz-se necessário compreender o desenvolvimento sustentável, cuja noção é permeada justamente por essa preocupação de um antropocentrismo desmedido, onde o homem considera que os recursos naturais são finitos e que a natureza estaria para servir o homem (SOCCOL; DUARTE, 2017).

A análise do desenvolvimento sustentável mostra-se bastante complexa nos dias atuais, de modo que se torna essencial a compreensão das questões ideológicas que fundamentam esse conceito para que seja possível interpretar o desenvolvimento sustentável enquanto um tema jurídico fundamental na Constituição Federal Brasileira (MARQUES; BARBOSA; ARAÚJO, 2017).

Nesse sentido, do ponto de vista jurídico, devem ser destacadas as características sociais, econômicas, pessoais e culturais fundamentais para uma vida humana digna e feliz. Do ponto de vista político, o conceito de desenvolvimento sustentável abarca as possibilidades elencadas pela Constituição Federal de aplicação de medidas pelo Poder Executivo e Legislativo, com a intervenção do Poder Judiciário em casos determinados, que visem a promoção do desenvolvimento sustentável. Para Folloni, essas noções são interdependentes, recursivas e autônomas (2014).

A tarefa de conceituar desenvolvimento sustentável é vista por Folloni (2014) como complexa. Para ele, o desenvolvimento sustentável configura uma temática de "estatura constitucional" de modo que sua compreensão é essencial para qualquer jurista. Avaliar e compreender como os programas estatais de desenvolvimento atuam de acordo com suas finalidades configura uma tarefa árdua, mas ao mesmo tempo relevante e difícil.

O debate sobre o desenvolvimento sustentável se tornou recorrente após a II Guerra Mundial. Após diversos encontros e compromissos ambientais envolvendo a política interna e global das Nações ao redor do globo, em 2015 foi instituída a Agenda 2030 para o Desenvolvimento Sustentável, que contém um conjunto de objetivos e metas de desenvolvimento sustentável. Nesse particular, a temática passou a ocupar um lugar de destaque nos discursos como um "meta-objetivo político" (MEADOWCROFT, 2000). O desenvolvimento sustentável consolidou-se como um conceito central, por ser "[...] ao mesmo tempo um caminho para entender o mundo e um método para resolver os problemas globais" (SACHS, 2018, p. 1).

Os objetivos de desenvolvimento sustentável elencados pela Agenda 2030 da ONU tem como escopo a concretização e a garantia dos direitos humanos de todos, a partir da 
adoção de ações transformadoras que se fazem extremamente e urgentemente necessárias para alcançar um mundo sustentável. Os objetivos são: acabar com a pobreza em todas as suas formas, em todos os lugares; acabar com a fome, alcançar a segurança alimentar e melhoria da nutrição e promover a agricultura sustentável; assegurar uma vida saudável e promover o bem-estar para todos, em todas as idades; assegurar a educação inclusiva e equitativa e de qualidade, e promover oportunidades de aprendizagem ao longo da vida para todos; alcançar a igualdade de gênero e empoderar todas as mulheres e meninas; assegurar a disponibilidade e gestão sustentável da água e saneamento para todos; assegurar o acesso confiável, sustentável, moderno e a preço acessível à energia para todos; promover o crescimento econômico sustentado, inclusivo e sustentável, emprego pleno e produtivo e trabalho decente para todos; construir infraestruturas resilientes, promover a industrialização inclusiva e sustentável e fomentar a inovação; reduzir a desigualdade dentro dos países e entre eles; tornar as cidades e os assentamentos humanos inclusivos, seguros, resilientes e sustentáveis; assegurar padrões de produção e de consumo sustentáveis; tomar medidas urgentes para combater a mudança do clima e seus impactos; conservação e uso sustentável dos oceanos, dos mares e dos recursos marinhos para o desenvolvimento sustentável; proteger, recuperar e promover o uso sustentável dos ecossistemas terrestres, gerir de forma sustentável as florestas, combater a desertificação, deter e reverter a degradação da terra e deter a perda de biodiversidade; promover sociedades pacíficas e inclusivas para o desenvolvimento sustentável, proporcionar o acesso à justiça para todos e construir instituições eficazes, responsáveis e inclusivas em todos os níveis e fortalecer os meios de implementação e revitalizar a parceria global para o desenvolvimento sustentável (ONU, 2019).

A concepção de desenvolvimento sustentável esteve historicamente interligada com debates envolvendo a proteção ambiental enquanto um aspecto limitador para o crescimento da economia. Contudo, essa visão hoje ultrapassa a noção de sustentabilidade apenas do ponto de vista da dimensão ambiental, cuja premissa é percebida pela simples análise dos objetivos de desenvolvimento sustentável acima elencados que não se direcionam apenas para a preocupação ambiental. Hoje, o desenvolvimento sustentável é anunciado com base em um tripé de dimensões, integradas e indivisíveis: a social, a econômica e a ambiental.

O desenvolvimento sustentável também vem sendo objeto de discussão perante o Poder Judiciário brasileiro, em especial, pelo Supremo Tribunal Federal. A partir de dados de pesquisa empírica realizada por Marques, Barbosa e Araújo (2017) foi possível verificar que a 
simples busca na base de dados da jurisprudência do STF, utilizando-se os argumentos “desenvolvimento sustentável”, foram encontrados quarenta acórdãos disponíveis. Pela análise do inteiro teor dos acórdãos, os referidos autores buscaram obter um conceito de desenvolvimento sustentável a partir do STF.

Nos acórdãos analisados, o desenvolvimento sustentável foi tratado como um princípio constitucional previsto no art. 225 da Constituição Federal, definido como “crescimento econômico com garantia paralela e superiormente respeitada da saúde da população, cujos direitos devem ser observados em face das necessidades atuais e daqueles previsíveis e a serem prevenidas para garantia e respeito às gerações futuras" (MARQUES; BARBOSA; ARAÚJO, 2017).

$\mathrm{Na}$ análise dos acórdãos pesquisados, o STF ratou o desenvolvimento sustentável como "de caráter eminentemente constitucional", considerado como um fator de obtenção do justo equilíbrio entre as exigências da economia e as da ecologia. Contudo, para o STF, a invocação do desenvolvimento sustentável, em caso de situações de conflitos entre valores constitucionais relevantes, não pode comprometer nem esvaziar o conteúdo essencial de um dos mais significativos direitos fundamentais, que é o direito à preservação do meio ambiente (MARQUES; BARBOSA; ARAÚJO, 2017).

É inegável que existam colisões entre direitos sob análise do Poder Judiciário, especialmente envolvendo o meio ambiente ecologicamente equilibrado. Dantas (2017) considera que, no momento do julgamento, assim como nos mais diversos ramos e áreas do Direito, os juízes são influenciados por suas convicções pessoais, ideologia ou até mesmo sua própria maneira de viver e ver o mundo. Na análise de lides ambientais, por exemplo, isso não é diferente, na medida em que há situações que envolvem conflitos de direitos com o meio ambiente, em que o julgamento se direciona ou para a tutela do meio ambiente ou para a proteção do desenvolvimento, ao direito de propriedade, ao patrimônio cultural, à separação dos poderes, entre outros.

$\mathrm{O}$ direito ao meio ambiente ecologicamente equilibrado frequentemente torna-se objeto de colisão com outros direitos fundamentais, como, por exemplo, o direito à manifestação cultural, à liberdade religiosa, ao desenvolvimento econômico, à livre iniciativa. Contudo, na situação em que ocorra colisão de princípios, é possível argumentar uma análise tanto em favor tanto de um quanto de outro direito colidente (DANTAS, 2017). 
No caso do meio ambiente, há quem defenda que "no confronto com outros interesses concorrentes, o meio ambiente deve ser considerado um interesse público preponderante, que, por sua colocação no sistema constitucional e jurídico, representa um objetivo social tido como prioritário" (SALLES, 1999).

Na concepção de Dantas (2017), não há sobreposição de um direito constitucional sobre outro, uma vez que nenhum deles é positivado como absoluto. É necessário analisar o caso concreto, com base na máxima da proporcionalidade, quando frustrada a tentativa de harmonização em caso de conflitos de direitos, na medida em que não se pode simplesmente aceitar, de forma genérica e abstrata, que um deles sempre prevalecerá sobre o outro.

Contudo, por mais que se verifique a importância de um desenvolvimento sustentável para equilíbrio do meio ambiente, ele não pode ser tomado como vetor absoluto. Isso pois, por vezes, outros interesses e direitos igualmente respaldados pela Constituição Federal confrontam com o desenvolvimento sustentável.

Ainda que a proteção ambiental não possa ser deixada de lado, os direitos fundamentais encontram-se em constante tensão e podem vir a ser objeto de colisão com o direito ao meio ambiente ecologicamente equilibrado. Entretanto, é necessário ter ciência de que, em todas as hipóteses, nenhum desses direitos está situado em posição hierarquicamente superior em relação ao outro (DANTAS, 2017).

Assim, analisados os conflitos entre o direito ao meio ambiente e desenvolvimento sustentável com outros direitos fundamentais, passa-se ao estudo das decisões do STF no âmbito da proteção aos animais e a relativização de direitos fundamentais.

\section{AS DECiSões do STF No ÂMBITO dA PROTEÇÃo AOS ANIMAIS E A RELATIVIZAÇÃO DE DIREITOS FUNDAMENTAIS}

Superada a análise inicial das nuances do meio ambiente ecologicamente equilibrado, utilizando-se de um desenvolvimento sustentável, e da possibilidade de conflito entre aquele e outros direitos, passa-se ao afunilamento da pesquisa, no âmbito da proteção dada aos animais no ordenamento jurídico pátrio com base nas decisões do Supremo Tribunal Federal, quando em conflito com direitos igualmente protegidos pela Constituição. 
Antes disso, deve-se destacar que o princípio da dignidade da pessoa humana não abrange tão somente a situação do indivíduo per si no meio social, mas também os demais elementos integrantes de uma mesma realidade político-social. Assim, é possível que a dignidade da pessoa humana possua uma dimensão ecológica, ou socioambiental. Dessa forma, tal postulado tem como objetivo assegurar um padrão de qualidade, equilíbrio e segurança ambiental (SARLET; FENSTERSEIFER, 2017).

Isso porque até mesmo no âmbito dos direitos humanos o meio ambiente integra um vértice desse projeto de sociedade sustentável na realidade contemporânea. (PINTO; COSTA, 2014).

Por mais que, como via de regra, exista uma visão antropocêntrica da dignidade da pessoa humana, dos direitos humanos ou até mesmo da sua concepção ecológica, a impossibilidade de se "objetificar" uma vida não pode, contudo, limitar-se à vida humana. (SARLET; FENSTERSEIFER, 2017).

Não é por acaso que a Carga Magna brasileira esculpe em seu art. 225, §1 ${ }^{\circ}$, VII, que incumbe ao Poder Público "proteger a fauna e a flora, vedadas, na forma da lei, as práticas que coloquem em risco sua função ecológica, provoquem a extinção de espécies ou submetam os animais a crueldade". Certo também é que a proteção animal é uma das grandes vertentes da abrangência do meio ambiente ecologicamente equilibrado, devendo fazer uso de um desenvolvimento sustentável suficientemente planejado.

No plano infraconstitucional, a Lei 5.197/67, estabelece que os animais são "propriedade do Estado, sendo proibida a sua utilização, perseguição, destruição, caça ou apanha", proibindo a caça profissional, considerada uma espécie de caça predatória. Ou seja, apesar da proteção ambiental estabelecida, percebe-se a "coisificação" da vida animal, tendo em consideração o período político em que se encontrava o país quando da sua edição.

A Lei 9.605/98, por sua vez, tipifica o crime de abuso, maus-tratos, ferimento, mutilação, experiência dolorosa ou cruel de animais. Se analisada a fundo, nem mesmo a criminalização de determinadas condutas contra os animais tem o condão de tornar o seu escopo biocêntrico. Ou seja, até mesmo a tipificação penal de práticas lesivas ao meio ambiente, e, in casu, aos animais, remetem à proteção preponderantemente humana.

A contrariu sensu, a Constituição Suíça, em seu artigo 120, chega a levar em consideração à dignidade da criatura, assim como a segurança dos animais e do meio ambiente. 
Correta a concepção suíça, uma vez que é insustentável imaginar o ser humano sem correlacioná-lo com o espaço ambiental e toda a cadeia de vida que fundamenta sua existência. A fragilização das bases naturais, por consequência, leva à vulneração da própria vida humana. (SARLET; FENSTERSEIFER, 2017).

Assim, se considerada a possibilidade de atribuir importância e direitos aos animais, como foco de preocupação jurídica, há de se levantar a problemática de conciliar a proteção animal com os interesses humanos e os conflitos decorrentes desse conflito. Exemplificativamente, a mesma Lei 5.197/67, já mencionada, abarca a possibilidade da caça de controle para reequilibrar as relações entre fauna e flora, manifestando a preponderância às relações humanas e sua economia.

Ainda, tem-se como praxe a autorização de comunidades indígenas à caça de subsistência, com proteção igualmente constitucional, nos termos do artigo 231 da Carta Maior. $^{2}$

É importante ressaltar que a tutela ambiental não pode sempre ser colocada em precedência absoluta, pois não está em relação de hierarquia para com outros direitos fundamentais. (DANTAS, 2017)

De uma maneira geral, o Supremo Tribunal Federal tem firmado o entendimento de que quando colidem interesses individuais com os coletivos, há de se dar preferência aos da coletividade, a exemplo da decisão no Mandado de Segurança no 25.284, do Distrito Federal.

Para além disso, nos últimos anos, diversas decisões da Suprema Corte brasileira têm colocado os animais no palco do debate protetivo, principalmente sopesando o interesse humano versus a proteção da fauna, conforme passa a se discorrer.

Como primeiro exemplo, cita-se o Recurso Extraordinário 153.531/SC, interposto contra decisão do Tribunal Catarinense que entendeu a "farra do boi" como uma manifestação cultural, motivo pelo qual os pedidos das requerentes não mereceriam ser providos. Tal julgamento é considerado o pioneiro da temática. Em seu voto, o Ministro Relator na Suprema Corte, Francisco Rezek, assevera que ao Estado foi atribuída a obrigação de proteger a fauna, seja administrativamente, seja legislando e que o Estado de Santa Catarina estaria sendo omisso ao cumprimento desse ditame constitucional, vez que é de ciência de toda a população em que consiste a mencionada festa e a que os animais são submetidos.

\footnotetext{
${ }^{2}$ Art. 231. São reconhecidos aos índios sua organização social, costumes, línguas, crenças e tradições, e os direitos originários sobre as terras que tradicionalmente ocupam, competindo à União demarcá-las, proteger e fazer respeitar todos os seus bens.
} 
Menciona, inclusive, que por mais que as requerentes sejam associações fluminenses, onde os problemas sociais são mais graves que a média brasileira e ainda assim tenham interposto ação civil pública contra prática considerada manifestação cultural em outro estado da federação (local em que ninguém havia se insurgido contra até então), a ninguém é dado o direito de estatuir a outrem qual dispositivo constitucional será eleito para se insurgir por atos ofensivos do Poder Público e buscar justiça.

O Ministro Marco Aurélio, por sua vez, ressaltou que não é uma manifestação cultural agasalhada pela Constituição, vez que "cuida-se de uma prática cuja crueldade é ímpar e decorre das circunstâncias de pessoas envolvidas por paixões condenáveis buscarem, a todo custo, o próprio sacrifício do animal".

Apesar do provimento do Recurso, não deve ser desconsiderado o voto vencido, do Ministro Maurício Corrêa, que firmou divergência no sentido de que a manifestação cultural também é constitucionalmente prevista pelo artigo $215, \S 1^{\circ}, \mathrm{CRFB} / 88$, e deve ser assegurada e respeitada, pois típica da região catarinense, e que "aí sim estar-se-ia violentando a Constituição Federal, caso se provesse o apelo". Tal voto, apesar de vencido, tem o condão de demonstrar que a disciplina não é consensual nem mesmo perante os Ministros da corte.

Já na Ação Direta de Inconstitucionalidade nº 2.514/SC, o Supremo Tribunal Federal entendeu não ser compatível com a Constituição do Brasil "a sujeição da vida animal a experiências de crueldade", declarando inconstitucional, por unanimidade, a Lei Catarinense $\mathrm{n}^{\mathrm{o}} 11.366 / 00$ que autorizava e regulamentava a criação e a exposição de aves de raça e a realização de "brigas de galo".

$\mathrm{Na}$ oportunidade, o Ministro Relator Eros Grau, em seu voto, afirmou que o legislador estadual ignorou o estatuído no artigo $225, \S 1^{\circ}$, VII, da CRFB/88, ao autorizar a “odiosa competição entre galos", refutando os argumentos da Assembleia Legislativa local que aduziu que o combate entre galos da espécie criada unicamente para esse fim "vive arraigado na cultura popular".

Ressalta-se que novas leis surgiram em âmbito estadual e municipal catarinense, tratando da temática, as quais foram declaradas inconstitucionais pelo próprio Tribunal de Justiça local.

Deste caso em diante, o Supremo passou a enfrentar diversas demandas de outros estados envolvendo a mesma prática "esportiva” envolvendo as aves da raça de rinha. 
Pela ADI no 3.776/RN, declarou-se inconstitucional, por unanimidade, a Lei Potiguar n 7.380/98, que também regulamentava as "rinhas" ou "brigas de galo". O Ministro Relator Cezar Peluso reafirmou que a Corte repudia a autorização ou regulamentação de "qualquer entretenimento que, sob justificativa de preservar manifestação cultural ou patrimônio genético de raças ditas combatentes, submeta animais a práticas violentas, cruéis ou atrozes, porque contrárias ao teor do artigo 225, §1, VII, da Constituição".

Ademais, o Procurador Geral da República, autor da referida ação, aduziu que a legislação potiguar andou no sentido contrário ao "de proteger a fauna, com a finalidade de assegurar a efetividade do direito ao meio ambiente ecologicamente equilibrado", promovendo uma competição cruel com os animais.

Seguindo o entendimento que se solidificava na Corte, no ano de 2011 foi julgada procedente a ADI $\mathrm{n}^{\circ} 1.856$, do Rio de Janeiro, para declarar inconstitucional e mesma prática de crueldade com aves combatentes (Lei Fluminense $n^{\circ} 2.895 / 98$ ), ressaltando-se que deve ser assegurado o direito à preservação da integridade do meio ambiente, ainda mais por possuir caráter metaindividual, considerado direito de terceira geração que consagra o postulado da solidariedade, que não pode ser descaracterizado pela manifestação cultural.

Afirma ainda que a tutela em tela é motivada justamente pela necessidade de impedir a ocorrência de situações de risco que ameacem ou que façam periclitar todas as formas de vida, não só a do gênero humano, mas, também, a própria vida animal, cuja integridade restaria comprometida, não fora a vedação constitucional, por práticas aviltantes, perversas e violentas contra os seres irracionais, como os galos de briga.

Já em 2016, no conturbado julgamento da ADI 4.983, do Ceará, discutiu-se a prática da vaquejada como manifestação cultural, regulamentada pela Lei Estadual no 15.299/13. Neste caso merece a atenção de que quatro dos ministros do Supremo divergiram quanto à declaração de inconstitucionalidade da vaquejada.

Em sede de decisão definitiva, o Pretório Excelso afirmou que a manifestação cultural não pode prescindir da observância da proteção ao meio ambiente esculpida no artigo 225. Aduziu o Relator, Ministro Marco Aurélio, que há expresso conflito entre as normas constitucionais (art. 225 e art. 215), informando que o meio ambiente sadio e equilibrado é dotado de altíssimo teor de humanismo e universalidade. 
O dever de proteger o meio ambiente, segundo ele, é “indisputável”, restando descobrir qual grau de sacrifício os indivíduos em geral podem e devem suportar para tornar efetivo esse direito.

Leciona ainda no sentido de que a crueldade intrínseca "não permite a prevalência de valores culturais como resultado desejado pelo sistema de direitos fundamentais da Carta de 1988."

Por sua vez, o Ministro Roberto Barroso afirmou, conforme já mencionado alhures, a visão antropocêntrica da proteção ao meio ambiente, que, contudo, é equilibrada pela Constituição nos parágrafos do artigo 225, que possuem caráter biocêntrico, tornando temperada a visão tradicional da proteção ambiental.

Contudo, referidos argumentos não foram seguidos pelos Ministros Gilmar Mendes, Edson Fachin, Luiz Fux e Dias Toffoli, que formaram a divergência no julgamento em questão.

O Ministro Gilmar Mendes inclusive menciona que a inconstitucionalidade resultaria em jogar na ilegalidade milhares de pessoas que se dedicam a essa atividade em caráter amador ou profissional, retirando-lhes o mínimo de lazer que às vezes se lhes propicia.

Assim, percebe-se que deixou de ser unânime no Supremo a interpretação de prevalência do meio ambiente (e em especial dos animais) quando em conflito com outros direitos fundamentais.

Na concepção de Dantas (2017), há de se ter em mente que as situações debatidas pelo Supremo Tribunal Federal nos casos mencionados merecem ser distinguidos entre si. Isso pois quando se discute a rinha de galo não se poderia sequer falar em colisão de princípios, pois não se trata de prática integrante do patrimônio cultural de qualquer tradição presente ou incorporada no Brasil. Nesse ponto, inclusive, o Tribunal decidiu diversas ações advindas de diferentes cantos do país sobre o assunto.

No tocante à farra do boi (e até mesmo a vaquejada), por outro lado, afirma sim haver colisão de princípios e direitos que merecem a ponderação, mas que a decisão da Corte ao julgar a prática catarinense como inconstitucional de maneira abstrata e sem dar brechas à representação cultural também pode ter suas falhas. Isso pois, de acordo com ele, é possível a manifestação cultural sem violência aos animais, como de fato acontecem em alguns municípios, bem como é possível a intervenção estatal para fiscalização dessas circunstâncias. 
A ideia de meio ambiente equilibrado não é incompatível com projetos de desenvolvimento econômico e/ou social que cuidem de preservá-lo como patrimônio da humanidade, podendo-se "afirmar que o meio ambiente pode ser palco para a promoção do homem todo e de todos os homens". (STF, AgR -MC-ACO 876/BA, Relator: Min. Menezes Direito, j. 19 dez. 2017).

Outrossim, os direitos fundamentais costumam colidir com a proteção ao meio ambiente, tornando-se terreno fértil para a aplicação da ponderação de princípios. (DANTAS, 2017).

Em esteira semelhante à já mencionada, denota-se que em 2019 o Supremo declarou, quando do julgamento do Recurso Extraordinário $\mathrm{n}^{\circ}$ 494.601, do Rio Grande do Sul, constitucional lei gaúcha permissiva de sacrifício de animais em rituais religiosos de matriz africana, uma vez que não há violência ou maus tratos aos animais sacrificados, não há desperdício de alimento, tampouco tem como fim o entretenimento das pessoas envolvidas, mas sim o exercício de um direito fundamental, que é o da liberdade religiosa. Fixou tese, inclusive, no sentido de que "é constitucional a lei de proteção animal que, a fim de resguardar a liberdade religiosa, permite o sacrifício ritual de animais em cultos de religiões de matriz africana".

Assim, a premissa afirmada anteriormente de que os direitos fundamentais individuais curvar-se-iam diante do meio ambiente, uma vez que coletivo, conforme asseverado pelo próprio Supremo, tende a encontrar novos entendimentos nos julgamentos recentes daquela corte.

Percebe-se que a manifestação cultural e a liberdade religiosa, por mais que pertençam a diferentes dimensões dos direitos fundamentais, possuem certa semelhança em seu cerne, vez que representam particularidades de determinados grupos e/ou pessoas que merecem ser respeitadas.

Dessa forma, percebe-se que a jurisprudência do Supremo, ainda que consolidada no sentido de proteção animal, tende a encontrar divergências e exceções, limitando assim a amplitude do referido agasalho constitucional ambiental em determinas situações, permanecendo tímido no tocante ao desenvolvimento sustentável nos fundamentos das decisões mencionadas. Assim, há de ser feita a ponderação no caso concreto, analisando em que circunstâncias os direitos e interesses individuais devem (e se devem) preponderar 
perante os da coletividade, mais precisamente ao meio ambiente, e, em específico, dos animais.

Tanto é assim que está na pauta para julgamento o da Ação Declaratória de Inconstitucionalidade $\mathrm{n}^{\circ}$ 5592, na qual é objeto a Lei 13.301/16 que autoriza a dispersão aérea de inseticidas contra o mosquito Aedes Aegypti. A ação, que ainda está aguardando o voto de todos os ministros. A relatora, Ministra Cármen Lúcia, proferiu seu voto em favor do meio ambiente e da fauna eventualmente a ser prejudicada com a medida, diante da falta de comprovação da efetividade da medida. Para ela, "tem-se quadro, pois, de insegurança jurídica e potencial risco de dano ao meio ambiente e à saúde humana pela previsão normativa de controle do mosquito Aedes aegypti pela dispersão de produtos químicos por aeronaves".

Dentre os votos já proferidos, percebe-se uma preferência pela improcedência da ação, sendo quatro o número de Ministros que já manifestaram seu voto pela constitucionalidade da lei, uma vez que a saúde pública e o meio ambiente estariam assegurados no texto da lei, pois condiciona a aplicação da medida à aprovação das autoridades sanitárias e à comprovação científica da eficácia da medida.

Constata-se então, que ainda há muito o que ser trabalhado para solucionar os conflitos da proteção ambiental com outros direitos fundamentais, principalmente quando em cheque outras situações existenciais.

Como explana a Ministra Rosa Weber, no julgamento da ADI 4.983, "longo é o caminho da humanidade e lento o avanço civilizatório, mas é preciso avançar, ainda que a passos lentos, ou, de preferência, não tão lentos assim."

Há que ser necessário um entendimento ecológico do direito, sendo a única revolução jurídica por meio da cultura e do verdadeiro engajamento cívico, superando tanto a hierarquia quanto a concorrência como narrativas "corretas" do ordenamento jurídico, sem se estar preso à qualquer concentração de poder ou pretensão de monopólio sobre o uso da força. (CAPRA; MATTEI).

As vozes que dão respaldo à proteção animal não ecoam de maneira uníssona, vez que, inclusive, dentre elas, encontram-se correntes contra os zoológicos, rodeios, criação de animais em massa, consumo de carne, entre outras atividades e/ou tradições que podem encontrar abrigo constitucional. Logicamente que a proteção aos animais não pode se dar de maneira absoluta, em detrimento à própria sobrevivência humana, vez que esta é o escopo do 
ordenamento jurídico, mas merece maior debate e aprofundamento quando se põe em cheque o conflito a outras premissas constitucionais.

\section{CONSIDERAÇÕES FINAIS}

O presente artigo teve como missão traçar uma linha de debate acerca do alcance do direito ao meio ambiente e do desenvolvimento sustentável, mais precisamente no âmbito das decisões do Supremo Tribunal Federal, relativas à proteção animal.

Em um primeiro momento, fortaleceu-se o estudo em torno do desenvolvimento sustentável, pautado nas dimensões clássicas da sustentabilidade, quais sejam: econômica, social e ecológica.

Percebe-se que a preocupação com os liames do meio ambiente com um desenvolvimento sustentável tem como escopo a própria permanência humana na Terra, garantindo às futuras gerações um nível de qualidade de vida saudável, dentro de um espaço ecologicamente protegido, sem inibir o desenvolvimento econômico, tampouco olvidando dos outros interesses sociais e coletivos.

Em que pese lute-se pela sobrevivência do meio ambiente e da importância que ele deve ter nos dias atuais, este não pode se tornar elemento absoluto do sistema jurídico, motivo pelo qual, pautado na proporcionalidade, deve-se realizar a ponderação de interesses em conflito, caso essa situação desemboque no Judiciário.

Não é possível colocar o homem como cerne do ordenamento jurídico, curvando-se a todos os seus desejos particulares. A dignidade da pessoa humana tem o papel fundamental de irradiar fundamentos básicos para a sobrevivência do homem, mas não pode limitar-se a ele. Ainda que fuja da sua própria terminologia, dever-se-ia reformular o conceito em debate para "dignidade da vida em quaisquer formas".

Assim, a proteção às demais formas de vida, e, em especial, à vida animal, merece proteção nos termos da Constituição, seja pelo artigo 225 e seus parágrafos, seja pela própria essência de Estado Democrático fundado na dignidade da pessoa humana.

Com base nisso e enfrentando a problemática proposta, demonstrou-se, na pesquisa, como o Supremo Tribunal Federal tem se posicionado quando do julgamento de demandas envolvendo a proteção ambiental dos animais, em especial aquelas em que a manifestação cultural e a liberdade religiosa estavam conflitando com os direitos ao meio ambiente. 
Viu-se que há uma tendência em julgar em favor da coletividade, vez que os direitos subjetivos particulares não podem, via de regra, ocasionar na degradação ao meio ambiente, mas que não há uma vertente sólida quanto a isso, pois cada caso concreto deve ser analisado dentro de suas particularidades.

Quando no ápice do debate ambiental, o Supremo tendeu a julgar por unanimidade em favor da proteção ambiental, cedendo, aos poucos, em favor de outros direitos nos últimos anos.

O desenvolvimento sustentável depende de um arcabouço de situações políticas, econômicas e sociais, mas que, por meio do controle judicial encontra uma forma de se manter hígido diante das intempéries legislativas ou administrativas dos entes da federação. Logicamente, como já mencionado, não se pode curvar-se em absoluto a qualquer direito, inclusive ao meio ambiente.

Assim, o Supremo Tribunal Federal acaba assumindo um papel fundamental no julgamento de tais ações, pois o próprio destino do meio ambiente e da vida animal pode ser alterado a depender do posicionamento da corte em cada caso concreto.

\section{REFERENCIAS}

BARBOSA, Fabio Coletti. Fundamentos da sustentabilidade. In: PEREIRA, Adriana Camargo; SILVA, Gibson Zucca da; CARBONARI, Maria Elisa Ehrhardt (Orgs.). Sustentabilidade, responsabilidade social e meio ambiente. São Paulo: Saraiva, 2011, p. 65-98.

BRASIL. Supremo Tribunal Federal. Ação Declaratória de Inconstitucionalidade 2.514/SC. Relator: Min. Eros Grau, j. 29 jun. 2005. Disponível em: 〈www.stf.jus.br〉. Acesso em 02 abr. 2019.

Ação Declaratória de Inconstitucionalidade 3.776-5/RN. Relator: Min. Cezar Peluso, j. 14 jun. 2007. Disponível em: 〈www.stf.jus.br〉. Acesso em 03 abr. 2019.

Ação Declaratória de Inconstitucionalidade 1.856/RJ. Relator: Min. Celso de Mello, j. 26 maio 2011. Disponível em: 〈www.stf.jus.br〉. Acesso em 03 abr. 2019.

Ação Declaratória de Inconstitucionalidade 4.983/CE. Relator: Min. Marco Aurélio, j. 06 out. 2016. Disponível em: 〈www.stf.jus.br〉. Acesso em 03 abr. 2019.

Ação Declaratória de Inconstitucionalidade 5592. Relatora: Min. Cármen Lúcia. Disponível em <www.stf.jus.br〉. Acesso em 11 abr. 2019. 
Agravo Regimental na Medida Cautelar na Ação Cível Originária $\overline{\text { 876/BA }}$. Relator: Min. Menezes Direito, j. 19 dez. 2007. Disponível em: 〈www.stf.jus.br $>$. Acesso em 03 abr. 2019.

Mandado de Segurança 25.284/DF. Relator: Min. Marco Aurélio, j. 17 jun. 2010. Disponível em: 〈www.stf.jus.br〉. Acesso em 02 abr. 2019.

Recurso Extraordinário 153.531/SC. Relator: Min. Francisco Rezek, j. 03

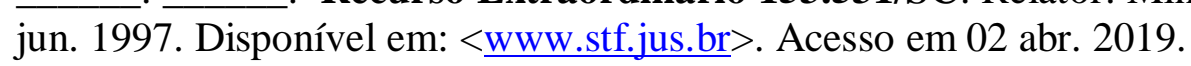

Recurso Extraordinário 494.601/RS. Relator: Min. Marco Aurélio, j. 28 mar. 2019. Disponível em: 〈www.stf.jus.br〉. Acesso em 03 abr. 2019.

CAMPINHO, Bernardo Brasil. O direito ao desenvolvimento como afirmação dos Direitos Humanos: demilitação, sindicabilidade e possibilidades emancipatórias. In: PIOVESAN, Flávia; SOARES, Inês Virgínia Prado (Coord.). Direito ao desenvolvimento. Belo Horizonte: Fórum, 2010, p. 153-177.

CAPRA, Fritjof; MATTEI, Ugo. A Revolução Ecojurídica. São Paulo: Editora Cultrix, 2018.

DANTAS, Marcelo Buzaglo. Direito Ambiental de Conflitos: o direito ao meio ambiente ecologicamente equilibrado e os casos de colisão com outros direitos fundamentais. 2a. ed. Rio de Janeiro: Lumen Juris, 2017.

FERREIRA FILHO, Manoel Gonçalves. Curso de Direito Constitucional. 37a ed. São Paulo: Saraiva, 2011.

FIORILlO, Celso Antonio Pacheco. Curso de Direito Ambiental Brasileiro. 12 ${ }^{\mathrm{a}}$ ed. São Paulo: Saraiva, 2011.

FOLLONI, André. A Complexidade ideológica, jurídica e política do desenvolvimento sustentável e a necessidade de compreensão interdisciplinar do problema. Revista Direitos Humanos Fundamentais, Osasco, jan./jun. 2014, ano 14, n.1, p.63-91.

LEITE, José Rubens Morato. Dano ambiental: do individual ao coletivo extrapatrimonial. 2. ed. São Paulo: Revista dos Tribunais, 2002.

MARQUES, Camila Salgueiro da Purificação; BARBOSA, Claudia Maria; ARAÚJO, Sylvia Maria Cortês Bonifácio de. O STF e o conceito de desenvolvimento sustentável: uma análise empírica. In: BETTES, Janaina Maria; FURIATTI, Luiza de Araújo; SOUZA, Maria Augusta Oliveira de. (Orgs.). O direito entre o desenvolvimento e a sustentabilidade. Curitiba: CRV, 2017, p. 33-52.

MIRRA, Álvaro Luiz Valery. Ação civil pública e a reparação do dano ao meio ambiente. São Paulo: Juarez de Oliveira, 2002.

JONAS, Hans. O princípio da responsabilidade. Ed. Contraponto, 1 ed. 2003. 
MEADOWCROFT, James. Sustainable development: a new (ish) idea for a new century? Political Studies, v. 48, n. 2, p. 370-387, 2000. Disponível em: < http://journals.sagepub.com/ doi/abs/10.1111/1467-9248.00265?journalCode=psxa >. Acesso em: 3 abr. 2019.

ORGANIZAÇÃO DAS NAÇÕES UNIDAS. Declaração sobre direito ao desenvolvimento. Disponível em: <http://www.direitoshumanos.usp.br/index.php/Direito-aoDesenvolvimento/declaracao-sobre-o-direito-ao-desenvolvimento.html>. Acesso em: 01 abr. 2019.

Transformando nosso mundo: a Agenda 2030 para o desenvolvimento sustentável. Disponível em: < https://nacoesunidas.org/pos2015/agenda2030/>. Acesso em 01 abr. 2019.

PINTO, João Batista Moreira; COSTA, Alexandre Bernardino. O Projeto dos Direitos Humanos, o Meio Ambiente e a Sustentabilidade. In: PINTO, João Batista Moreira; COSTA, Alexandre Bernardino (Orgs.) Bases da Sustentabilidade: os direitos humanos. 2a. ed. Rio de Janeiro: Lumen Juris, 2014.

SACHS, Jeffrey D. From Millennium Development Goals to Sustainable Development Goals. The Lancet, v. 379, n. 9832, p. 2206-2211, 2012. Disponível em: <http://www.thelancet.com/journals/lancet/article/PIIS0140-6736(12)60685-0/abstract>. Acesso em: 28 mar. 2018.

SALLES, Carlos Alberto de. Execução judicial em matéria ambiental. São Paulo: Revista dos Tribunais, 1999.

SARLET, Ingo Wolfgang; FENSTERSEIFER, Tiago. Princípios do direito ambiental. 2a. ed. São Paulo: Saraiva, 2017.

SOCCOL, Flávia Thomas; DUARTE, João Guilherme Holzmann A atuação do Estado nos estudos de impacto ambiental e o desenvolvimento econômico. In: BETTES, Janaina Maria; FURIATTI, Luiza de Araújo; SOUZA, Maria Augusta Oliveira de. (Orgs.). O direito entre o desenvolvimento e a sustentabilidade. Curitiba: CRV, 2017, p. 53-68.

SUÍÇA. Constituição Federal da Confederação Suíça de 1999. Disponível em: < https://www.ccisp-newsletter.com/wp docs/Bundesverfassung PT.pdf>. Acesso em 02 abr. 2019. 